\title{
A violação da imagem na perspectiva do Direito Penal Alemão
}

\author{
The violation of the image from the perspective of German \\ criminal law
}

Leonardo Estevam de Assis Zanini ${ }^{1}$

\begin{abstract}
RESUMO
O presente artigo analisa o surgimento e o desenvolvimento da proteção da imagem no direito penal alemão. Destaca que a defesa da imagem no direito penal alemão foi prevista já no início do século XX, com a promulgação a Lei sobre os Direitos de Autor em Obras de Artes Plásticas e Fotografia (KUG). O texto enfatiza que no âmbito do direito penal é necessária a compreensão da teoria do bem jurídico como instrumento de limitação da intervenção criminal. Apresenta reflexões acerca dos bens jurídicos tutelados e das condutas incriminadas pelo § 201a do Código Penal alemão. Feita uma análise geral quanto à legitimidade e necessidade da tutela penal, o texto estuda a relação entre o direito à imagem e a proteção da vida privada. Por fim, analisa o registro não autorizado de cenas de nudez ou de pornografia.
\end{abstract}

\section{PALAVRAS-CHAVE:}

Proteção penal da imagem; direito à vida privada; direito penal alemão; direitos da personalidade; pornografia infanto-juvenil; abuso sexual.

\begin{abstract}
This article analyzes the emergence and development of the protection of the image in the German criminal law. It emphasizes that the defense of the image in the German criminal law was foreseen in the beginning of the 20th century, with the enactment of the Law on the Protection of Copyright in Works of Art and Photographs (KUG). The text highlights that the understanding of criminal law demands the study of the theory of legal good as an instrument to limit criminal intervention. It presents reflections on the protected legal good and the conduct incriminated by $\S 201 \mathrm{a}$ of the German Penal Code. The text also studies the relation between
\end{abstract}

\footnotetext{
${ }^{1}$ Livre-docente e doutor em Direito Civil pela USP. Pós-doutorado em Direito Civil pelo Max-Planck-Institut für ausländisches und internationales Privatrecht (Alemanha). Pós-doutorado em Direito Penal pelo Max-PlanckInstitut für ausländisches und internationales Strafrecht (Alemanha). Doutorando em Direito Civil pela AlbertLudwigs-Universität Freiburg (Alemanha). Mestre em Direito Civil pela PUC-SP. Bacharel em Direito pela USP. Juiz Federal. Professor Universitário. Pesquisador do grupo Novos Direitos CNPq/UFSCar. Autor de livros e artigos publicados nas áreas de Direito Civil, Direitos Intelectuais e Direito do Consumidor. Foi bolsista da MaxPlanck-Gesellschaft e da CAPES. Foi Delegado de Polícia Federal, Procurador do Banco Central do Brasil, Defensor Público Federal, Diretor da Associação dos Juízes Federais de São Paulo e Mato Grosso do Sul e Diretor Acadêmico da Escola de Formação e Aperfeiçoamento de Servidores da Justiça Federal em São Paulo.
} 
the right to the image and the protection of the privacy. Finally, it analyzes the unauthorized recording of nudity or pornography scenes.

\section{KEYWORDS:}

Criminal protection of the image; privacy; german criminal law; personality rights; child pornography; sexual abuse.

\section{INTRODUÇÃO}

O presente texto objetiva apresentar um panorama do tratamento jurídico-penal dado pelo direito alemão ao direito à imagem. A evolução da temática está associada aos novos desenvolvimentos técnico-científicos, que levaram também a um grande avanço dos ataques aos direitos da personalidade, particularmente sob a forma de gravação, de armazenamento e de utilização massificada da imagem digitalizada em redes de computadores.

As ameaças decorrentes do progresso técnico-científico foram percebidas precocemente na Alemanha, que já no início do século XX promulgou sua primeira lei tipificando penalmente a violação do direito à imagem. Na segunda metade do século $\mathrm{XX}$, em face dos riscos cada vez mais elevados à imagem e à privacidade, provocados pela sociedade de massas e pelas inovações tecnológicas, voltou à ordem do dia, no Parlamento alemão (Deutscher Bundestag), a discussão sobre a renovação da legislação. Tal debate culminou com a introdução, no Código Penal alemão (Strafgesetzbuch - StGB), do § 201a, dispositivo que claramente ampliou a proteção penal dada ao direito à imagem ${ }^{2}$.

Ao admitir a renovação do sistema de tutela penal da imagem, o legislador alemão certamente levou em conta a temática atinente à legitimidade da intervenção jurídico-criminal, que é sempre uma premissa para a análise da tipicidade de determinado comportamento.

Outrossim, sem deixar de analisar os questionamentos supra, mesmo porque a pertinência da tutela penal da imagem em face do caráter fragmentário e subsidiário do direito penal é um problema fundamental em relação ao tema que se coloca, o presente artigo cuida do

\footnotetext{
${ }^{2}$ WESSELS, Johannes; HETTINGER, Michael. Strafrecht Besonderer Teil. 41. ed. Heidelberg: C.F. Müller, 2017, v. 1, p. $183-184$.
} 
estudo dos dispositivos penais que permitem ao direito positivo alemão a proteção penal da imagem.

Destarte, o objeto do trabalho é a análise da proteção penal da imagem na Alemanha desde seu surgimento, no início do século XX, até as modificações mais recentes da legislação, ocorridas em 2015, traçando um panorama do direito positivo daquele país, cuja investigação se pautará pela pesquisa da doutrina e da jurisprudência.

\section{O SURGIMENTO DA PROTEÇÃO PENAL DA IMAGEM NA ALEMANHA}

A introdução de um dispositivo legal para a proteção penal da imagem na Alemanha gerou muita discussão na doutrina, surgindo no início do século XX, depois de amplo debate parlamentar. A lacuna legal, verificada nos casos "Dame im Badekostüm" e "Otto von Bismarck", muito contribuiu para que a tutela da imagem não fosse restringida apenas ao âmbito do direito civil, mas também encontrasse força na seara penal ${ }^{3}$.

De fato, parte dos estudiosos entendia que o direito à própria imagem merecia tutela tanto civil quanto penal, fazendo-se necessária uma legislação que outorgasse essa dupla proteção. Em sentido oposto havia o grupo que recusava a proteção penal, pois não desejava a imediata proteção pelo direito penal de um bem jurídico que ainda estava em construção. Os integrantes desse grupo consideravam, desse modo, que a solução do direito civil poderia resolver a maioria dos problemas e, naqueles casos de particular importância, entraria em cena o tipo penal da ofensa (Beleidigung), já existente à época no Código Penal alemão ( $\$ 185$ do Código Penal alemão) $)^{4}$.

Esse último posicionamento preconizava que o tipo penal de ofensa deveria ser ampliado, tal qual ocorreu no antigo direito privado romano, quando o espectro de proteção da

\footnotetext{
${ }^{3}$ SCHMITZ, Albert. Strafrechtlicher Schutz vor Bild- und Wortaufnahmen. Hamburg: Dr. Kovac, 2011, p 17-18.

${ }^{4}$ KRAENZ, Nadja, Der strafrechtliche Schutz des Persönlichkeitsrechts, p. 93.
} 
actio iniuriarum foi aumentado, passando a abranger todas as lesões relevantes a um direito corpóreo ou incorpóreo ${ }^{5}$.

Todavia, a ideia de ampliação do alcance do tipo penal de ofensa não saiu vencedora, uma vez que seus opositores deixaram muito bem explanado que a redução dessas condutas ao crime de ofensa estreitaria a proteção demandada apenas para os casos em que houvesse violação da honra. Com isso, a proposta deixaria de tutelar a liberdade de autodeterminação do indivíduo, que teria seu bem jurídico ofendido e não disporia da proteção criminal nos casos de publicação não autorizada da imagem. Ademais, levantou-se o problema relacionado à impossibilidade de aplicação do tipo nos casos em que o agente não tinha consciência da prática da ofensa. Isso tudo foi suficiente para convencer o parlamento alemão da necessidade de um novo tipo penal ${ }^{6}$.

Sucedeu então a promulgação em 1907 da Lei sobre os Direitos de Autor em Obras de Artes Plásticas e Fotografia (Kunsturhebergesetz - KUG), que previu, em seu $\S 33$, pela primeira vez, a proteção da imagem na esfera penal. Diferentemente do que ocorreu em muitas legislações, pode-se afirmar que a KUG realmente concedeu uma tutela penal autônoma da imagem, que foi considerada um bem jurídico independente. Assim sendo, para que a imagem fosse protegida penalmente não se fazia necessária a ofensa a nenhum outro bem jurídico, particularmente a vida privada ou a intimidade.

\section{CRÍTICAS AO $\$ 33$ DA LEI 1907}

O $§ 33$ da KUG prevê: “(1) Com pena de privação da liberdade de até um ano ou multa é punido quem, contrariamente aos $\S \S 22,23$, divulga ou exibe publicamente uma imagem. (2) O delito somente é perseguido por requerimento" 7 .

\footnotetext{
${ }^{5}$ ZANINI, Leonardo Estevam de Assis. A tutela das criações intelectuais e a existência do direito de autor na Antiguidade Clássica. Revista Eletrônica da Faculdade de Direito de Franca, v. 8, n. 1, jul. 2013, p. 140.

${ }^{6}$ KRAENZ, Nadja, Der strafrechtliche Schutz des Persönlichkeitsrechts, p. 94.

${ }^{7} \S 33$ da KUG (com redação em vigor a partir de 1 de janeiro de 1975): “(1) Mit Freiheitsstrafe bis zu einem Jahr oder mit Geldstrafe wird bestraft, wer entgegen den $\$ \$ 22,23$ ein Bildnis verbreitet oder öffentlich zur Schau stellt. (2) Die Tat wird nur auf Antrag verfolgt".
} 
Como se pode notar, o tipo mencionado não descreve completamente a conduta punível, dependendo de complementação dos $\S \S 22$ e 23 da mesma lei, aos quais faz expressa referência. Assim sendo, diante da necessidade de complementação e considerando que o $§ 22$ da KUG vedava apenas a divulgação e a exposição pública da imagem alheia sem a autorização ${ }^{8}$, restaram sem punição as condutas de simplesmente captar ou produzir arbitrariamente a imagem alheia, não obstante tais atos fossem abrangidos pela proteção civil dada ao direito à própria imagem ${ }^{9}$.

A falta de previsão legal da punição da captação ou da produção arbitrárias da imagem alheia também não poderia ser resolvida pela extensão do tipo penal do $\S 33$, pois no direito penal alemão, tal como no brasileiro, é proibida a analogia (nullum crimen sine lege scripta) ${ }^{10}$.

Igualmente, não se poderia considerar a captação ou a produção da imagem como tentativa do delito em questão, visto que o sistema penal alemão diferencia os crimes (Verbrechen) dos delitos (Vergehen) e somente pune a tentativa de prática de um delito se vier expressamente prevista na lei $(\S 12$, alínea 2 combinado com $\S 23$, alínea 1, ambos do Código Penal alemão) ${ }^{11}$. Dessa forma, como o $§ 33$ da KUG é um delito e não há previsão de incriminação da tentativa, a captação ou a produção da imagem não poderiam ser reprimidas no âmbito dessa disposição penal ${ }^{12}$, o que levava muitos a considerar que a fotografia não autorizada, no máximo, poderia ser punida como uma forma de ofensa (Beleidigung) ${ }^{13}$.

\footnotetext{
${ }^{8}$ LEFFLER, Ricarda, Der strafrechtliche Schutz des Rechts am eigenen Bild vor dem neuen Phänomen des CyberBullying, p. 61.

${ }^{9}$ VALERIUS, Brian. § 201a. In: LAUFHÜTTE, Heinrich Wilhelm et alii. Strafgesetzbuch. Leipziger Kommentar. 12 ed. Berlin: De Gruyter, 2010, v. 6, p. 1394.

${ }^{10}$ HELLE, Jürgen, Besondere Persönlichkeitsrechte im Privatrecht, p. 69.

${ }^{11} \S \S 12$, alíneas 1 e 2 do Código Penal: "Verbrechen und Vergehen. (1) Verbrechen sind rechtswidrige Taten, die im Mindestmaß mit Freiheitsstrafe von einem Jahr oder darüber bedroht sind. (2) Vergehen sind rechtswidrige Taten, die im Mindestmaß mit einer geringeren Freiheitsstrafe oder die mit Geldstrafe bedroht sind". Tradução livre: "Crimes e delitos. (1) Crimes são atos ilícitos aos quais são cominadas, no mínimo, uma pena privativa de liberdade de um ano ou mais. (2) Delitos são atos ilícitos aos quais são cominadas, no mínimo, uma reduzida pena privativa de liberdade ou uma multa".

§ 23, alínea 1 do Código Penal: "Strafbarkeit des Versuchs. (1) Der Versuch eines Verbrechens ist stets strafbar, der Versuch eines Vergehens nur dann, wenn das Gesetz es ausdrücklich bestimmt". Tradução livre: "Punibilidade da tentativa. (1) A tentativa de um crime é sempre punível, a tentativa de um delito somente é punível se a lei expressamente determinar".

${ }^{12}$ LEGLER, Thomas, La vie privée, image volée, p. 120.

13 KARGL, Walter. Zur Differenz zwischen Wort und Bild im Bereich des strafrechtlichen Persönlichkeitsschutzes. Zeitschrift für die Gesamte Strafrechtswissenschaft, v. 117, n. 2, p. 324-353, nov. 2005, p. 326.
} 
Também se apresenta bastante problemática, em função da existência de norma penal em branco, a não exigência de consentimento quando se está diante de "fotografias da área da história contemporânea" ("Bildnisse aus dem Bereich der Zeitgeschichte"), o que pode ser contraposto pela existência de "interesse legítimo" que possa justificar a proibição da publicação ou da exposição.

Outrossim, deve-se ainda destacar que, apesar da existência de numerosas decisões civis fundamentadas nos $\S \S 22$ e 23 da KUG, no âmbito penal não há quase nenhum julgado aplicando o $\S 33$ da KUG. A falta de significado prático da disposição deve-se provavelmente ao fato de que o tipo em questão foi considerado um delito de ação penal privada ( $\$ 374$, inciso 1, 8 do Código de Processo Penal - Strafprozessordnung - StPO), o que gera elevados riscos relacionados com os custos do processo penal ${ }^{14}$.

Outro aspecto que merece referência é o fato de que, em muitos casos, a captação ou a produção da imagem já poderiam representar uma lesão ao direito geral da personalidade (Allgemeines Persönlichkeitsrecht), o que se agravava ainda mais pela dificuldade da proteção cível nesses casos. É que uma tutela inibitória (Unterlassungsklage), com a finalidade de prevenção de uma divulgação iminente da imagem captada, demandaria a comprovação da existência de intenção de publicá-la, o que, pela dificuldade da prova, tornava inadequado tal tipo de instrumento protetivo ${ }^{15}$.

Desse modo, graças à insatisfatória posição da vítima do delito do $§ 33$ da KUG, aceitouse que o recurso à disposição penal tinha predominantemente a função de auxiliar na interpretação do direito civil ${ }^{16}$.

\footnotetext{
${ }^{14} \mathrm{O}$ caso mais conhecido que tratou da aplicação do $\S 33$ da KUG foi decidido em 1920 e envolveu a publicação de fotos do Presidente e do Ministro da Defesa do Reich em trajes de banho. O tribunal não considerou a conduta punível, argumentando que as fotos publicadas na revista foram tiradas em local público (LEFFLER, Ricarda, Der strafrechtliche Schutz des Rechts am eigenen Bild vor dem neuen Phänomen des Cyber-Bullying, p. 61).

15 KARGL, Walter. Zur Differenz zwischen Wort und Bild im Bereich des strafrechtlichen Persönlichkeitsschutzes. Zeitschrift für die Gesamte Strafrechtswissenschaft, v. 117, n. 2, p. 324-353, nov. 2005, p. 324.

${ }^{16}$ É interessante notar que, na tentativa de remediar o problema, propôs-se um projeto de lei, no ano de 2004, que tirava o delito do $\S 33$ da seara dos delitos de ação privada, passando-se a norma para o círculo dos delitos processados por requerimento do lesado (KRAENZ, Nadja, Der strafrechtliche Schutz des Persönlichkeitsrechts, p. 96).
} 


\section{AS TENTATIVAS DE AMPLIAÇÃO DA PROTEÇÃO PENAL DA IMAGEM}

Com a entrada em vigor do $\S 33$ da KUG, a doutrina que pretendia a ampliação da proteção penal da imagem passou um bom tempo sem muita manifestação. O tema voltou a ser discutido somente em 1958, quando o governo tentou criar, num projeto de alteração da legislação, o § 103a do Código Penal alemão, que foi conhecido como "Lex Soraya". A proposta foi, contudo, rejeitada pelo Parlamento alemão ${ }^{17}$.

Na década seguinte, em face dos riscos cada vez mais elevados à privacidade, provocados pela moderna sociedade de massa e pelo desenvolvimento de novos meios tecnológicos, voltou à ordem do dia a discussão sobre os delitos contra a vida privada ${ }^{18}$. A despeito do debate, o Projeto de Código Penal, elaborado pelo governo em 1962, era totalmente omisso em relação à imagem, considerando desnecessária sua tutela pela codificação, pois as previsões do direito civil e do direito penal acessório já seriam suficientes para tanto ${ }^{19}$.

Em 1971, com inspiração no art. 179quarter do Código Penal suíço (Schweizerisches Strafgesetzbuch), tentou-se aprovar um Projeto Alternativo, que regulava conjuntamente, em seu $\S 146$, os casos em que houvesse escuta ou captação de imagem sem autorização. Entendiase que ambos os bens jurídicos mereciam a mesma valoração e proteção, bem como que a gravidade da ameaça a tais bens jurídicos não mais admitia que sua proteção fosse relegada ao direito civil ou ao direito penal acessório. No entanto, a disposição em questão jamais foi adotada, não passando de mera proposta legislativa ${ }^{20}$.

Em seguida, durante a grande reforma do direito penal, em 1974, o tema voltou a ser ventilado. Todavia, ainda que parte dos estudiosos exigisse a criação da figura, mais uma vez saiu vitorioso o entendimento no sentido de que não havia nenhuma necessidade urgente de introdução de uma nova disposição atinente ao direito à imagem. Por outro lado, foi introduzido no Código Penal alemão o $§ 201$, que tipificou a gravação e a escuta não autorizadas da palavra

\footnotetext{
${ }^{17}$ KÄCHELE, Andreas, Der strafrechtliche Schutz vor unbefugten Bildaufnahmen (\$ 201a StGB), p. 45.

${ }^{18}$ HENGST, Florian, Der strafrechtliche Schutz des Rechts am eigenen Bild (\$ 201a StGB), p. 76.

${ }^{19}$ EISELE, Jörg. Strafrechtlicher Schutz vor unbefugten Bildaufnahmen. Juristische Rundschau, Berlin, p. 6-11, jan. 2005, p. 6.

${ }^{20}$ LEGLER, Thomas, La vie privée, image volée, p. 119.
} 
de outra pessoa (Verletzung der Vertraulichkeit des Wortes). Isso criou uma assimetria entre a tutela penal da imagem e da palavra, visto que a última passou a contar com ampla proteção ${ }^{21}$.

Depois da tentativa frustrada de 1974, apesar do fato de que muitos estudiosos estavam convencidos de que se fazia necessária a ampliação da proteção e a criação de um novo tipo penal, não surgiu, durante muito tempo, nenhuma proposta de legislação digna de menção. $\mathrm{O}$ tema somente voltou a ser debatido nos trabalhos da Comissão Federal para Proteção de Dados, que notou, nos relatórios dos anos de 1999 e 2000, um grande avanço dos ataques aos direitos da personalidade graças ao desenvolvimento de novas técnicas de vídeo e da internet ${ }^{22}$.

Por conseguinte, em 2001, após provocação do Estado de Baden-Württemberg, e diante da necessidade de medidas contra gravações não autorizadas de imagens de pessoas em áreas reservadas de domicílios, em provadores de lojas e em banheiros, que foram posteriormente publicadas na internet, a discussão acerca da necessidade legislativa retomou sua marcha ${ }^{23}$.

\section{A INTRODUÇÃO DO § 201a NO CÓDIGO PENAL ALEMÃO}

A $36^{\text {a }}$ Lei de alteração do Código Penal (36. Strafrechtsänderungsgesetz - StrÄG), de 30 de julho de 2004, introduziu o $§ 201$ a, que entrou em vigor em 6 de agosto de 2004. O dispositivo ampliou a proteção penal dada ao direito à imagem, que até então encontrava fundamento legal no $\S 33$ da KUG, que incriminava apenas a divulgação e a exibição de imagens sem o consentimento da pessoa retratada ${ }^{24}$.

A despeito dos avanços, deve-se destacar que a proposta original de criação do parágrafo tinha em vista uma proteção bem mais ampla da imagem, o que acabou não ocorrendo, visto que no decorrer da tramitação legislativa a proposição inicial foi sendo alterada, particularmente

\footnotetext{
${ }^{21}$ LEFFLER, Ricarda, Der strafrechtliche Schutz des Rechts am eigenen Bild vor dem neuen Phänomen des CyberBullying, p. 64.

${ }^{22}$ EISELE, Jörg. Strafrechtlicher Schutz vor unbefugten Bildaufnahmen. Juristische Rundschau, Berlin, p. 6-11, jan. 2005, p. 6.

${ }^{23}$ KÄCHELE, Andreas, Der strafrechtliche Schutz vor unbefugten Bildaufnahmen (\$ 201a StGB), p. 47.

${ }^{24}$ RENGIER, Rudolf. Strafrecht Besonderer Teil II. 14. ed. München: C. H. Beck, 2013, p. 265.
} 
em função do forte lobby da imprensa. Desse modo, o texto aprovado acabou prevendo uma tutela inferior àquela apresentada originariamente ${ }^{25}$.

O tipo foi introduzido na seção 15 da Parte Especial do Código Penal alemão, que cuida da violação da vida privada e do segredo (Verletzung des persönlichen Lebens- und Geheimbereichs). Nessa linha, constou expressamente na fundamentação do projeto de lei que devia ser protegida a área de reserva do ser humano diante de lesão pela reprodução da sua imagem $^{26}$.

O novo tipo complementou o conjunto de disposições penais que visam à garantia de uma esfera individual própria como uma área livre, imprescindível para o desenvolvimento da personalidade humana ${ }^{27}$. E o reforço da tutela penal da imagem se mostrava mesmo oportuno, em especial diante das novas tecnologias desenvolvidas nas últimas décadas (câmeras e filmadoras digitais, canetas com câmeras espiãs, smartphones, internet, drones etc), que facilitaram a captação, a gravação e a divulgação de imagens ${ }^{28}$.

Assim sendo, da mesma forma como foi necessária a criação da KUG em função do desenvolvimento da fotografia, também se fez mister a introdução do § 201a do Código Penal para conter as ofensas perpetradas ao direito à imagem por meio dos novos equipamentos e recursos atualmente disponíveis, que permitem até mesmo a divulgação mundial da imagem em tempo real pela internet ${ }^{29}$.

\footnotetext{
${ }^{25}$ HENGST, Florian, Der strafrechtliche Schutz des Rechts am eigenen Bild ( $\$ 201$ a StGB), p. 91.

${ }^{26}$ BOSCH, Nikolaus. Der strafrechtliche Schutz vor Foto-Handy-Voyeuren und Paparazzi. Juristenzeitung, v. 60, n. 8, p. 377-385, abr. 2005, p. 377.

27 KARGL, Walter. Zur Differenz zwischen Wort und Bild im Bereich des strafrechtlichen Persönlichkeitsschutzes. Zeitschrift für die Gesamte Strafrechtswissenschaft, v. 117, n. 2, p. 324-353, nov. 2005, p. 331.

${ }^{28}$ GRAF, Jürgen-Peter. Vor $\S 201$ ff. §§ 201-202c. In: Münchener Kommentar zum Strafgesetzbuch. 2. ed. München: C. H. Beck, 2012, v. 4, p. 143.

${ }^{29}$ WESSELS, Johannes; HETTINGER, Michael. Strafrecht Besonderer Teil. 41. ed. Heidelberg: C.F. Müller, 2017, v. 1, p. 183.
} 


\section{AS CONDUTAS TÍPICAS PREVISTAS PELO § 201a DO CÓdIGO PENAL ALEMÃO}

O § 201a do Código Penal alemão previu a punibilidade da violação ao direito à imagem, normalmente a associando a uma lesão à esfera estritamente pessoal da vida. Constam condutas típicas nos incisos do $§ 201$ a do Código Penal alemão, valendo lembrar que tais disposições foram bastante alteradas por legislação que entrou em vigor em janeiro de 2015 (49. Gesetz zur Änderung des $S t G B-\operatorname{Str} \ddot{A} G)^{30}$, senão vejamos:

Pune-se com pena privativa de liberdade de até dois anos ou com multa, conforme determina o inciso 1, alínea 1, do $\S 201 \mathrm{a}$, a conduta daquele que "produzir ou transmitir fotos não autorizadas de uma outra pessoa, que se encontre em uma habitação ou em um local especialmente protegido contra a vista, ferindo, com isso, a esfera estritamente pessoal de sua vida" 31 .

Nessa linha, o tipo abrange a reprodução da realidade por meio de qualquer equipamento que permita o armazenamento da imagem em um suporte físico, como é o caso da fotografia, do vídeo, do cinema, da televisão ou mesmo da memória de um computador. Assim sendo, toda conduta que não corresponda à real captação ou reprodução da imagem não é abrangida pelo tipo, como é o caso de caricaturas, de desenhos feitos à mão ou de pinturas ${ }^{32}$.

No que toca ao verbo transmitir, a norma proíbe todo tipo de transmissão da imagem, ainda que não haja seu armazenamento duradouro no suporte físico, como se dá nas transmissões em tempo real pela internet, que partem de webcams ou até mesmo de spycams $^{33}$.

\footnotetext{
${ }^{30}$ WESSELS, Johannes; HETTINGER, Michael. Strafrecht Besonderer Teil. 41. ed. Heidelberg: C.F. Müller, 2017, v. 1, p. 184.

${ }^{31}$ Vejamos o original do $\$ 201 \mathrm{a},(1)$ : "Mit Freiheitsstrafe bis zu zwei Jahren oder mit Geldstrafe wird bestraft, wer: 1. von einer anderen Person, die sich in einer Wohnung oder einem gegen Einblick besonders geschützten Raum befindet, unbefugt eine Bildaufnahme herstellt oder überträgt und dadurch den höchstpersönlichen Lebensbereich der abgebildeten Person verletzt,".

${ }^{32}$ VALERIUS, Brian. § 201a. In: LAUFHÜTTE, Heinrich Wilhelm et alii. Strafgesetzbuch. Leipziger Kommentar. 12 ed. Berlin: De Gruyter, 2010, v. 6, p. 1396.

${ }^{33}$ WESSELS, Johannes; HETTINGER, Michael. Strafrecht Besonderer Teil. 41. ed. Heidelberg: C.F. Müller, 2017, v. 1, p. 182.
} 
Também se deve notar que, diferentemente do que ocorre no âmbito do direito civil, a disposição penal não exige a reconhecibilidade da pessoa para a proteção, sendo punível a reprodução de imagens de partes do corpo, como é o caso das características sexuais, mesmo que não seja possível a identificação da pessoa $^{34}$. Em sentido contrário, há na doutrina quem defenda que o tipo somente assume relevo se a pessoa pode ser reconhecida na imagem. Ademais, vale ainda destacar que a disposição não pune fotos tiradas de objetos, como documentos e o mobiliário ${ }^{35}$.

No inciso 1, alínea 2, do $§ 201 \mathrm{a}$, que faz parte das inovações da legislação que entrou em vigor em 2015, pune-se, com pena privativa de liberdade de até dois anos ou com multa, a conduta daquele que produzir ou transmitir fotos não autorizadas, que exibem o desamparo de uma outra pessoa, ferindo, com isso, a esfera estritamente pessoal da vida da pessoa retratada ${ }^{36}$.

Esse novo tipo ampliou a esfera de proteção da imagem no direito penal alemão, que sofria sérias restrições em função da alínea 1, que somente punia a conduta se a pessoa se encontrasse em uma habitação ou em um local especialmente protegido contra a vista ${ }^{37}$. Agora, como o tipo nada menciona sobre o local onde a imagem foi produzida, são puníveis condutas como tirar uma foto de uma pessoa extremamente alcoolizada em público ou ainda de uma pessoa que foi vítima de um crime violento e está caída na calçada ${ }^{38}$.

O inciso 1, alínea 3, do $§ 201 \mathrm{a}$, por sua vez, incrimina a conduta daquele que utiliza ou torna acessível a um terceiro uma imagem produzida em infração ao disposto nas duas alíneas anteriores $^{39}$. Vê-se então que a variante prevista nesse inciso está associada à conduta do indivíduo que não produziu a imagem, mas posteriormente a utilizou ou a tornou acessível a terceiros ${ }^{40}$.

\footnotetext{
${ }^{34}$ VALERIUS, Brian. § 201a. In: LAUFHÜTTE, Heinrich Wilhelm et alii. Strafgesetzbuch. Leipziger Kommentar. 12 ed. Berlin: De Gruyter, 2010, v. 6, p. 1397.

${ }^{35}$ KINDHÄUSER, Urs. Strafrecht. Besonderer Teil I. 8 ed. Baden-Baden: Nomos, 2017, p. 227.

${ }^{36}$ Vejamos o original do §201a, (1): "Mit Freiheitsstrafe bis zu zwei Jahren oder mit Geldstrafe wird bestraft, wer: 2. eine Bildaufnahme, die die Hilflosigkeit einer anderen Person zur Schau stellt, unbefugt herstellt oder überträgt und dadurch den höchstpersönlichen Lebensbereich der abgebildeten Person verletzt,"”.

${ }^{37}$ EISELE, Jörg. Strafrecht - Besonderer Teil I. 4. ed. Stuttgart: Kohlhammer, 2017, p. 236-237.

${ }^{38}$ WESSELS, Johannes; HETTINGER, Michael. Strafrecht Besonderer Teil. 41. ed. Heidelberg: C.F. Müller, 2017, v. 1, p. 185.

${ }^{39}$ Vejamos o original do §201a, (1): "Mit Freiheitsstrafe bis zu zwei Jahren oder mit Geldstrafe wird bestraft, wer: 3. eine durch eine Tat nach den Nummern 1 oder 2 hergestellte Bildaufnahme gebraucht oder einer dritten Person zugänglich macht oder".

${ }^{40}$ EISELE, Jörg. Strafrecht - Besonderer Teil I. 4. ed. Stuttgart: Kohlhammer, 2017, p. 237.
} 
Complementando as disposições do inciso 1, do § 201a, pune-se, na alínea 4, com pena privativa de liberdade de até dois anos ou com multa, a conduta daquele que, com autorização, produz uma imagem referida nas alíneas 1 ou 2, mas que a utiliza ou a torna acessível a um terceiro sem autorização, ferindo a esfera estritamente pessoal da vida ${ }^{41}$.

Como se pode notar de uma leitura mais atenta das disposições mencionadas, a conduta daquele que simplesmente observa outra pessoa em sua casa acaba não sendo abrangida, enquanto a produção de uma imagem sob as mesmas condições é punível ${ }^{42}$. A explicação para tal distinção está no fato de que a mera observação a olho nu (frecher Blick) pode ser certamente considerada como um atentado à decência, mas não representa uma lesão ao bem jurídico passível de punição pelo direito penal ${ }^{43}$.

No inciso 2, do § 201a, outra inovação da legislação de 2015, pune-se, com as mesmas penas das disposições anteriores, a conduta daquele que torna acessível a terceiros uma foto susceptível de causar danos consideráveis à reputação da pessoa que foi retratada sem autorização $^{44}$. São fotos em situações indignas ou muito desagradáveis ou, ainda, tiradas em tal estado que a pessoa não gostaria de vê-las chegar ao conhecimento de terceiros ${ }^{45}$.

Por derradeiro, o inciso 5, do $\S 201$ a permite a apreensão e o perdimento dos suportes materiais que foram utilizados na fixação da imagem. Desse modo, os equipamentos e outros meios técnicos empregados pelo agente ou partícipe podem ser apreendidos e perdidos, permitindo-se a aplicação do $§ 74$ a do Código Penal alemão ${ }^{46}$.

\footnotetext{
${ }^{41}$ Vejamos o original do §201a, (1): "Mit Freiheitsstrafe bis zu zwei Jahren oder mit Geldstrafe wird bestraft, wer: 4. eine befugt hergestellte Bildaufnahme der in den Nummern 1 oder 2 bezeichneten Art wissentlich unbefugt einer dritten Person zugänglich macht und dadurch den höchstpersönlichen Lebensbereich der abgebildeten Person verletzt".

${ }^{42}$ HOYER, Andreas. Die Verletzung des höchstpersönlichen Lebensbereichs bei § 201a StGB. Zeitschrift für Internationale Strafrechtsdogmatik, ano 1, n. 1, p. 1-6, jan. 2006, p. 4.

${ }^{43}$ VALERIUS, Brian. § 201a. In: LAUFHÜTTE, Heinrich Wilhelm et alii. Strafgesetzbuch. Leipziger Kommentar. 12 ed. Berlin: De Gruyter, 2010, v. 6, p. 1403.

${ }^{44}$ Vejamos o original do §201a, (2): "Ebenso wird bestraft, wer unbefugt von einer anderen Person eine Bildaufnahme, die geeignet ist, dem Ansehen der abgebildeten Person erheblich zu schaden, einer dritten Person zugänglich macht".

${ }^{45}$ WESSELS, Johannes; HETTINGER, Michael. Strafrecht Besonderer Teil. 41. ed. Heidelberg: C.F. Müller, 2017, v. 1, p. 185.

${ }^{46}$ Vejamos o original do §201a, (5): "Die Bildträger sowie Bildaufnahmegeräte oder andere technische Mittel, die der Täter oder Teilnehmer verwendet hat, können eingezogen werden. \$ 74 a ist anzuwenden”.
} 


\section{A TENTATIVA DE EQUIPARAÇÃO ENTRE A TUTELA PENAL DA IMAGEM E DA PALAVRA}

O legislador procurou equiparar a proteção dada à imagem àquela até então concedida pelo § 201 do Código Penal alemão à confidencialidade da palavra (Verletzung der Vertraulichkeit des Wortes), que pune "a gravação e a audição não consentidas da palavra de outra pessoa" ${ }^{47}$. A nova disposição buscava dar tutela penal análoga tanto à imagem quanto à palavra falada, eliminando as disparidades existentes ${ }^{48}$.

A equiparação da proteção da imagem e da palavra falada se fazia mesmo urgente, bastando aqui um exemplo para que se compreenda a problemática: se um ginecologista gravasse filmes das consultas feitas em suas pacientes, somente seria típica sua conduta se o filme também contivesse a gravação em áudio, uma vez que o direito penal então vigente punia a gravação de áudio, mas considerava fato atípico a mesma conduta se o bem jurídico fosse a imagem $^{49}$.

O § 201a modificou esse quadro, retirando a lacuna da lei penal e passando a proteger a pessoa contra não somente a transmissão não autorizada da sua imagem, mas também contra a simples produção dessa imagem. A ampliação da proteção quanto à simples produção da imagem também se espelhou na disposição do § 201, que anteriormente já considerava punível a conduta de simplesmente gravar a voz ${ }^{50}$.

Acrescente-se ainda que o tipo do $\S 201 \mathrm{a}$, inciso 1, alínea 1, exige que a imagem tenha sido captada quando a pessoa se encontrava em sua moradia ou em uma área particularmente protegida da visão alheia ${ }^{51}$, o que guarda correspondência com a limitação do $§ 201$, relativa à palavra não falada publicamente ("das nichtöffentlich gesprochene Wort"), bem como deixa

\footnotetext{
${ }^{47}$ ANDRADE, Manuel da Costa. A tutela penal da imagem na Alemanha e em Portugal. Revista Brasileira de Ciências Criminais, v. 94, 2012, p. 144.

${ }^{48}$ HOYER, Andreas. Die Verletzung des höchstpersönlichen Lebensbereichs bei § 201a StGB. Zeitschrift für Internationale Strafrechtsdogmatik, ano 1, n. 1, p. 1-6, jan. 2006, p. 1.

${ }^{49}$ RENGIER, Rudolf. Strafrecht Besonderer Teil II. 14. ed. München: C. H. Beck, 2013, p. 265.

${ }^{50}$ HOYER, Andreas. Die Verletzung des höchstpersönlichen Lebensbereichs bei § 201a StGB. Zeitschrift für Internationale Strafrechtsdogmatik, ano 1, n. 1, p. 1-6, jan. 2006, p. 1.

${ }^{51}$ SCHMITZ, Albert, Strafrechtlicher Schutz vor Bild- und Wortaufnahmen, p. 26.
} 
clara a orientação desses conceitos pela ideia de esfera íntima, tal qual vinha sendo utilizado nas decisões cíveis da Corte Constitucional (Bundesverfassungsgericht) ${ }^{52}$.

De qualquer forma, ainda que seja juridicamente razoável o tratamento de um atentado ao direito à palavra falada de forma similar ao atentado ao direito à imagem, é certo que as diferenças entre esses dois bens jurídicos são evidentes, valendo aqui, apenas para exemplificar, lembrar que a captação da imagem é possível pela simples presença física da pessoa, enquanto que o registro da voz demanda que a pessoa a ser registrada tenha uma conduta ativa ${ }^{53}$. Por isso, apenas com essa observação, já se mostra necessário todo cuidado quando se procura equiparar a proteção penal desses bens jurídicos.

\section{TUTELA PENAL AUTÔNOMA DO DIREITO À IMAGEM}

Em uma análise mais acurada do tipo penal, pode-se notar que a legislação não está protegendo a imagem como bem jurídico autônomo. Exige que a imagem tenha sido capturada e que isso implique em atentado à esfera estritamente pessoal da vida ${ }^{54}$, ou ainda que a violação envolva imagens de pessoas nuas e menores de dezoito anos ${ }^{55}$.

Desse modo, o direito penal alemão condiciona a resposta sancionatória à ofensa da imagem em associação com o desrespeito da esfera estritamente pessoal ou com o desrespeito à intimidade. Assim sendo, não há que se falar em uma previsão criminal que tutele a imagem como um bem jurídico autônomo, independente de qualquer violação à privacidade e à intimidade, pois isso configuraria, conforme aponta parte da doutrina, violação à proibição de excesso (Übermaßverbot $)^{56}$.

\footnotetext{
${ }^{52}$ RENGIER, Rudolf, Strafrecht Besonderer Teil II, p. 267.

${ }^{53}$ LEGLER, Thomas, La vie privée, image volée, p. 3.

${ }^{54}$ WESSELS, Johannes; HETTINGER, Michael. Strafrecht Besonderer Teil. 41. ed. Heidelberg: C.F. Müller, 2017, v. 1, p. 182.

${ }^{55}$ KINDHÄUSER, Urs. Strafrecht. Besonderer Teil I. 8 ed. Baden-Baden: Nomos, 2017, p. 230.

${ }^{56}$ VALERIUS, Brian. § 201a. In: LAUFHÜTTE, Heinrich Wilhelm et alii. Strafgesetzbuch. Leipziger Kommentar. 12 ed. Berlin: De Gruyter, 2010, v. 6, p. 1398.
} 
Nessa linha, deve-se reconhecer que se está diante de um tipo penal que tutela mais de um bem jurídico, também chamado de delito pluriofensivo. Não há então que se falar na entrada em vigor de um dispositivo penal que tenha reconhecido uma proteção de forma autônoma ao direito à imagem. $\mathrm{O}$ que existe é a proteção da imagem se "a sua utilização ou transmissão arbitrárias lesem a área nuclear da intimidade" 57.

Por conseguinte, verifica-se que o tipo protege o direito à própria imagem como uma forma de manifestação do direito geral da personalidade, mas exige, para tanto, que simultaneamente também haja desrespeito à esfera estritamente pessoal da vida ou à intimidade. Fica então evidente que a imagem não é um bem jurídico tutelado de forma autônoma pelo direito penal alemão. Ademais, deve-se reconhecer que o $§ 201$ a completou o disposto no $\S 33$ da KUG, que deixava de fora da tutela penal a produção da imagem, pois somente tipificava a divulgação e a exposição ${ }^{58}$.

\section{O BEM JURÍDICO PROTEGIDO}

A intervenção do direito penal existe para garantir ao cidadão uma convivência livre e pacífica, bem como para a manutenção dos direitos fundamentais previstos constitucionalmente. $\mathrm{O}$ direito penal não pode proibir nada além daquilo que seja estritamente necessário para que se atinja uma coexistência livre e pacífica ${ }^{59}$.

Para justificar a intervenção do direito penal é muito defendida a teoria do bem jurídico, que associa a existência de uma disposição penal ao conceito de bem jurídico. A teoria do bem jurídico como instrumento para restringir a intervenção do direito penal encontrou eco na doutrina moderna ${ }^{60}$, não obstante o posicionamento contrário de respeitáveis estudiosos ${ }^{61}$.

\footnotetext{
${ }^{57}$ ANDRADE, Manuel da Costa. A tutela penal da imagem na Alemanha e em Portugal. Revista Brasileira de Ciências Criminais, v. 94, 2012, p. 139.

${ }^{58}$ EISELE, Jörg. Strafrecht - Besonderer Teil I. 4. ed. Stuttgart: Kohlhammer, 2017, p. 234.

${ }^{59}$ ROXIN, Claus. Strafrecht: Allgemeiner Teil, v. 1, p. 16.

${ }^{60}$ RENGIER, Rudolf. Strafrecht Allgemeiner Teil, p. 14-15.

${ }^{61}$ Há autores que negam que a função do direito penal é a proteção de bens jurídicos ou mesmo que possa existir um conceito seguro do que eles sejam. De fato, conforme assevera Figueiredo Dias, a noção de bem jurídico "não pôde, até o momento presente, ser determinada - e talvez jamais o venha a ser - com uma nitidez e segurança que
} 
De fato, o conceito de bem jurídico, conforme posicionamento prevalente na Alemanha, designa os valores ideais que justificam a existência do tipo penal ${ }^{62}$. A incriminação de um comportamento deve sempre corresponder a pelo menos uma ameaça a um bem jurídico. No entanto, nem toda ameaça a um bem jurídico justifica a criação de um tipo penal ${ }^{63}$.

O legislador não é livre para criar tipos penais. É que os bens jurídicos protegidos pelo direito penal devem considerar-se concretizações dos valores constitucionais ligados aos direitos e deveres fundamentais, bem como à ordem social, política e econômica ${ }^{64}$. Isso significa que o legislador está vinculado às diretrizes estabelecidas na Lei Fundamental, não podendo criminalizar, sem qualquer critério ou parâmetro, toda e qualquer conduta humana.

De fato, para a tipificação e a punição criminal dos ataques à imagem é necessário que sejam respeitados, logicamente, os princípios constitucionais limitadores do direito de punir, como, por exemplo, o princípio da taxatividade (Bestimmtheitsgebot), que exige a descrição clara e precisa do comportamento incriminado, o princípio da proporcionalidade (Verhältnismäßigkeit), que reclama cominação de pena adequada ao grau de reprovabilidade da conduta e do resultado, ou ainda o princípio da fragmentariedade (fragmentarischer Charakter des Strafrechts), pelo qual nem todo ataque ao bem jurídico deve ser criminalizado, mas tão somente aqueles reputados de especial gravidade ${ }^{65}$.

Ora, respeitados os princípios constitucionais, é concedida então uma ampla liberdade ao legislador para a definição dos bens jurídicos que merecem tutela penal. E partindo dessa possibilidade, tem sido tendência nos países europeus a punição da violação do direito à imagem na medida de sua relevância como atentado à reserva da vida privada e da intimidade ${ }^{66}$.

\footnotetext{
permita convertê-la em conceito fechado e apto à subsunção, capaz de traçar, para além de toda a dúvida possível, a fronteira entre o que legitimamente pode e não pode ser criminalizado" (DIAS, Jorge de Figueiredo. Direito penal: parte geral, t. I, p. 114). Na Alemanha, igualmente, sustenta Hirsch que há uma imprecisão conceitual sobre o que seja bem jurídico, razão pela qual ele não pode funcionar como critério limitador do direito penal. Stratenwerth, por sua vez, observa que, dada a multiplicidade conceitual do bem jurídico, há insegurança jurídica na sua utilização como valor norteador da atividade legiferante repressiva. Jackobs, um dos mais conhecidos opositores da teoria do bem jurídico, defende que a função do direito penal não é proteger bens jurídicos, mas sim garantir o império do sistema normativo desafiado pelo cometimento da infração penal (ROXIN, Claus. A Proteção de bens jurídicos como função do direito penal, p. 14-15).

62 KINDHÄUSER, Urs. Strafrecht: Allgemeiner Teil, p. 37.

${ }^{63}$ KÄCHELE, Andreas, Der strafrechtliche Schutz vor unbefugten Bildaufnahmen (\$ 201a StGB), p. 55.

${ }^{64}$ DIAS, Jorge de Figueiredo. Direito penal: parte geral, t. I, p. 120.

${ }^{65}$ RENGIER, Rudolf. Strafrecht Allgemeiner Teil, p. 9-10 e 20-21.

${ }^{66}$ ZANINI, Leonardo Estevam de Assis. Direito à imagem, p. 357.
} 
Diante disso, os tipos constantes dos $\S \S 201$ e seguintes do Código Penal alemão se alinham pela proteção tanto do direito geral da personalidade (Allgemeines Persönlichkeitsrecht) como do direito à autodeterminação informacional (Recht auf informationelle Selbstbestimmung). São esses bens jurídicos que estão em primeiro plano quando se fala na proteção contra a ofensa às esferas pessoal e secreta da vida ${ }^{67}$.

No que toca especificamente ao tipo do $§ 201 \mathrm{a}$, partindo das disposições constitucionais acima mencionadas, chega-se, como bens jurídicos tutelados, ao direito à proteção da vida privada, da intimidade e ao direito à própria imagem. Assim sendo, o legislador alemão reconhece que a pessoa necessita de uma determinada área livre da indiscrição alheia para o desenvolvimento de sua personalidade ${ }^{68}$.

Atentos à temática da norma, há estudiosos que consideram que o bem jurídico protegido seria apenas a esfera estritamente pessoal da vida privada ou a intimidade, não indicando o direito à própria imagem como bem jurídico a ser tutelado ${ }^{69}$.

Todavia, a disposição penal evidentemente não tutela somente a esfera estritamente pessoal da vida privada ou a intimidade, pois se fosse assim também deveriam ser incriminadas as condutas que reproduzissem a imagem de objetos, como seria o caso de fotos tiradas do quarto de um casal que acabou de se retirar do leito. Nessa linha, fica claro que a tutela é voltada para o resguardo da imagem de pessoas, o que encontra fundamento na própria confiança que se exige nas relações sociais.

Desse modo, considerando a necessidade da intersecção desses bens jurídicos, podemos concluir que não é todo tipo de imagem e nem todo comportamento atinente à vida privada ou intimidade que a norma penal protege. Assim sendo, sempre será necessária a investigação do conteúdo da imagem, uma vez que a compreensão do bem jurídico-penal exige a ocorrência de uma determinada danosidade social.

67 KÜHL, Kristian. Zur Strafbarkeit unbefugter Bildaufnahmen. AfP - Zeitschrift für Medien- und Kommunikationsrecht, Düsseldorf, ano 35, n. 3, p. 190-197, maio/jun. 2004, p. 193.

${ }^{68}$ WESSELS, Johannes; HETTINGER, Michael. Strafrecht Besonderer Teil. 41. ed. Heidelberg: C.F. Müller, 2017, v. 1, p. 182.

${ }^{69}$ VALERIUS, Brian. § 201a. In: LAUFHÜTTE, Heinrich Wilhelm et alii. Strafgesetzbuch. Leipziger Kommentar. 12 ed. Berlin: De Gruyter, 2010, v. 6, p. 1395. 


\section{A ESFERA ESTRITAMENTE PESSOAL DA VIDA}

Os estudiosos do direito penal, na época dos debates relacionados à aprovação do § 201a do Código Penal alemão, não se ocuparam muito com uma exata definição da esfera de proteção e, ao invés disso, preocupados com os limites da tutela penal, indicaram setores da vida que necessitavam de resguardo, como os atinentes à família, à sexualidade e à saúde.

$\mathrm{Na}$ tentativa de evitar as discussões relacionadas às esferas tradicionalmente indicadas pela doutrina e jurisprudência, o $§ 201$ a do Código Penal alemão tipificou a produção e a transmissão de imagens de uma pessoa captadas em sua esfera estritamente pessoal da vida (höchstpersönliche Lebensbereich) ${ }^{70}$.

Com isso, o termo esfera estritamente pessoal da vida foi cunhado pelo legislador alemão, pois se temia que a utilização do conceito de esfera íntima pudesse levar a uma compreensão muito restrita da tutela penal, associando-a tão somente à proteção da nudez e da sexualidade ${ }^{71}$.

Todavia, o temor, pelo menos em parte, não se justificava, visto que o conceito de esfera íntima não era utilizado nas decisões cíveis com conotação tão restrita, abrangendo não somente aspectos relacionados à sexualidade e nudez, mas também atinentes à saúde e ao falecimento. A precaução apenas fazia sentido quando se observava que as decisões do Tribunal Federal de Justiça (Bundesgerichtshof - BGH) não incluíam os acontecimentos da vida familiar no conceito de intimidade, tratando-os no âmbito da vida privada ${ }^{72}$.

Diante de todos esses questionamentos, é de se observar que tal conceito, considerando a teoria das esferas, acabou gerando mais debates do que soluções, já que anteriormente não havia sido utilizado em nenhum texto legal. A polêmica continua viva, visto que não há uma

\footnotetext{
${ }^{70}$ GERTZEN, Anke Marie. Der strafrechtliche Schutz des Rechts am eigenen Bild: Eine Bewertung des $\S 201$ a StGB im Vergleich zu Art. 197 Código Penal, p. 90.

${ }^{71}$ RENGIER, Rudolf. Strafrecht Besonderer Teil II, p. 267.

${ }^{72}$ HOYER, Andreas. Die Verletzung des höchstpersönlichen Lebensbereichs bei $§ 201 \mathrm{a}$ StGB. Zeitschrift für Internationale Strafrechtsdogmatik, ano 1, n. 1, p. 1-6, jan. 2006, p. 3.
} 
definição clara proposta pela doutrina e também não se pode reconhecer a existência de jurisprudência firme sobre o assunto ${ }^{73}$.

Há, entretanto, estudiosos e julgados que se orientam pela ideia de esfera íntima da pessoa, que abrangeria a proteção de áreas como: saúde, morte, sexualidade, pensamentos, sentimentos e outros temas ligados à área nuclear e inviolável da personalidade ${ }^{74}$. Nisso, acabam repetindo as decisões proferidas pelo Tribunal Federal de Justiça (BGH) em questões atinentes à intimidade, de maneira que por essa interpretação o conceito de "esfera estritamente pessoal" acaba não trazendo nada de novo e também não contribui para que haja uma maior clareza da norma. Desse modo, teria sido então melhor a utilização da expressão "esfera íntima" 75 .

Outrossim, é de se destacar que a relevância prática da delimitação da esfera estritamente pessoal é bastante significativa, já que não há que se falar na conduta típica, no caso do $§ 201$ a, inciso 1, alínea 1, daquele que captura imagens alheias em locais públicos, o que demonstra a necessidade do estabelecimento de critérios precisos do âmbito de atuação da disposição penal ${ }^{76}$. Assim sendo, entende-se que o tipo penal mencionado somente incrimina a conduta daquele que realmente houver provocado lesão à esfera estritamente pessoal da vida através da violação do direito à imagem, o que indica se tratar de um delito de dano (Verletzungsdelikt) e não de um delito de perigo abstrato (abstraktes Gefährdungsdelikt ${ }^{77}$.

Por conseguinte, diante dos questionamentos levantados, é certo que o § 201a do Código Penal alemão sofreu e ainda sofre severas críticas da doutrina, visto que seu âmbito de proteção, com a inclusão do novo conceito de esfera estritamente pessoal da vida, não apresentou a segurança jurídica desejável ${ }^{78}$.

\footnotetext{
73 KARGL, Walter. Zur Differenz zwischen Wort und Bild im Bereich des strafrechtlichen Persönlichkeitsschutzes. Zeitschrift für die Gesamte Strafrechtswissenschaft, v. 117, n. 2, p. 324-353, nov. 2005, p. 337.

${ }^{74}$ KINDHÄUSER, Urs. Strafgesetzbuch. Lehr- und Praxiskommentar. 5. ed. Baden-Baden: Nomos, 2012, p. 740. 75 BORGMANN, Matthias. Von Datenschutzbeauftragten und Bademeistern - Der strafrechtliche Schutz am eigenen Bild durch den neuen § 201a StGB. Neue Juristische Wochenschrift, Frankfurt, ano 57, n. 30, p. 21332135, jul. 2004, p. 2134.

${ }^{76}$ DREYER, Gunda; KOTTHOFF, Jost; MECKEL, Astrid. Urheberrecht. 3. ed. Heidelberg: C. F. Müller, 2013, p. 1706-1707.

${ }^{77}$ VALERIUS, Brian. § 201a. In: LAUFHÜTTE, Heinrich Wilhelm et alii. Strafgesetzbuch. Leipziger Kommentar. 12 ed. Berlin: De Gruyter, 2010, v. 6, p. 1406.

${ }^{78}$ DREYER, Gunda; KOTTHOFF, Jost; MECKEL, Astrid, Urheberrecht, p. 1705.
} 


\section{LOCAIS PROTEGIDOS}

A delimitação dos locais de proteção também é um ponto muito importante no que toca à tutela penal da imagem e encontra certa ressonância nos ensinamentos atinentes à vitimologia, visto que a pessoa que se coloca em público deve contar com a possibilidade de ser fotografada mais facilmente ${ }^{79}$.

A premissa certamente não difere da sistemática empregada na proteção da palavra falada e do sigilo das correspondências, visto que aquele que fala em público ou que permite o conhecimento pelo público do teor de uma carta não conta com proteção penal na Alemanha.

Também é relevante observarmos que a restrição da esfera de proteção apenas a determinados locais constitui uma limitação da tutela penal, mas, por outro lado, igualmente garante que o ius puniendi estatal não se ocupará de um bem jurídico que não seja realmente digno e carecedor de defesa.

De qualquer forma, vale lembrar que ainda resta a possibilidade de proteção tanto pelo direito civil como pelo $\S 33$ da KUG para os casos de imagens não tuteladas pelo $§ 201 \mathrm{a}$ do Código Penal alemão ${ }^{80}$.

Destarte, a limitação à reprodução de imagens atinentes apenas a determinada esfera espacial, constante do § 201a, inciso 1, alínea 1, acaba, na prática, facilitando a valoração dos comportamentos dignos de proteção penal e também proporciona uma melhor observância do princípio da certeza jurídica ${ }^{81}$.

\footnotetext{
${ }^{79}$ EISELE, Jörg. Strafrechtlicher Schutz vor unbefugten Bildaufnahmen. Juristische Rundschau, Berlin, p. 6-11, jan. 2005, p. 8.

${ }^{80}$ VALERIUS, Brian. § 201a. In: LAUFHÜTTE, Heinrich Wilhelm et alii. Strafgesetzbuch. Leipziger Kommentar. 12 ed. Berlin: De Gruyter, 2010, v. 6, p. 1399.

${ }^{81}$ BOSCH, Nikolaus. Der strafrechtliche Schutz vor Foto-Handy-Voyeuren und Paparazzi. Juristenzeitung, v. 60, n. 8, p. 377-385, abr. 2005, p. 377.
} 


\section{A REPRESSÃO CONTRA A PORNOGRAFIA INFANTO-JUVENIL}

Após a realização de uma investigação judicial no início de 2014 contra o deputado socialdemocrata Sebastian Edathy, por suposto envolvimento com pornografia infantil, o Ministério da Justiça alemão resolveu apresentar um projeto de lei para o fortalecimento da repressão contra a prática de pornografia infanto-juvenil e de abuso sexual, projeto que acabou resvalando também no § 201a do Código Penal alemão.

No caso em questão, apesar da investigação, as imagens gravadas nos discos rígidos de computadores, que foram apreendidos em apartamentos e no escritório do político, não foram consideradas passíveis de enquadramento na legislação penal ( $\$ 184$ b do Código Penal alemão). É que os filmes e fotografias de meninos nus, com idades entre nove e quatorze anos, adquiridos de uma loja online no Canadá, não poderiam ser classificados como pornografia infantil, cuja punição está prevista no Código Penal alemão. O material encontrado estaria no limiar da ilegalidade, mas seria penalmente irrelevante, dado que a exposição explícita de crianças não era uma conduta tipificada, mesmo porque não mostrava atividade sexual.

Como decorrência do caso Edathy, e na tentativa de aprimoramento das disposições penais, particularmente para coibir a atuação de pedófilos, surgiu um projeto de lei de alteração do Código Penal alemão. Referido projeto foi aprovado em janeiro de 2015, tendo reestruturado e ampliado as disposições do $§$ 201a do Código Penal alemão (49. Gesetz zur Änderung des $S t G B)^{82}$.

Entre as alterações, foi acrescentado o inciso 3 ao $§ 201$ a do Código Penal alemão, punindo com prisão de até dois anos ou multa aquele que produz ou oferece, com objetivos comerciais, imagens de pessoas nuas com menos de dezoito anos ${ }^{83}$.

\footnotetext{
82 WESSELS, Johannes; HETTINGER, Michael. Strafrecht Besonderer Teil. 41. ed. Heidelberg: C.F. Müller, 2017, v. 1, p. 184.

${ }^{83}$ Vejamos o original do §201a, (3): "Mit Freiheitsstrafe bis zu zwei Jahren oder mit Geldstrafe wird bestraft, wer eine Bildaufnahme, die die Nacktheit einer anderen Person unter achtzehn Jahren zum Gegenstand hat, 1. herstellt oder anbietet, um sie einer dritten Person gegen Entgelt zu verschaffen, oder 2. sich oder einer dritten Person gegen Entgelt verschafft".
} 
A alteração veio em boa hora, havendo mesmo dignidade penal para a proteção dessas imagens, o que também guarda consonância com o sistema até então construído na Alemanha, que associa a tutela penal da imagem com a intimidade, na qual se incluiriam os vídeos e as fotos dessas pessoas desnudas, independentemente do local em que ocorra o seu registro.

Destarte, o comércio de tais imagens constitui uma grave violação dos direitos de personalidade das crianças e dos adolescentes, merecendo aplauso o novo tipo constante do inciso 3 do $§ 201$ a do Código Penal alemão.

\section{CONSIDERAÇÕES FINAIS}

A miniaturização e aperfeiçoamento dos aparelhos de captação e gravação de imagens facilitou sobremaneira a produção instantânea de vídeos e fotos de alta qualidade. Ao lado dessas novas técnicas, também houve a ampliação das possibilidades de divulgação das imagens e vídeos, especialmente por meio da internet.

Diante disso, é necessária uma clara delimitação entre as condutas a serem incriminadas e aquelas que não devem ser tipificadas pelo direito penal, pois só assim haverá um satisfatório cumprimento do princípio da segurança jurídica (Bestimmtheitsgebot). Não resta dúvida, entretanto, quanto à necessidade de utilização do direito penal como um segundo pilar de sustentação da proteção da imagem.

Nesse contexto, o § 201a do Código Penal alemão foi criado para conter as ofensas perpetradas ao direito à imagem, particularmente aquelas praticadas com o uso de novas tecnologias. A legislação alemã conta com um tipo penal voltado especificamente para a tutela da imagem, o que diverge do ordenamento jurídico brasileiro, onde existe uma constelação de normas tratando da imagem, que no fim das contas mais prejudicam a tutela penal desse bem jurídico.

O direito penal alemão não reconhece uma previsão criminal que tutele a imagem como um bem jurídico autônomo, independente de qualquer violação à honra, à privacidade ou à 
intimidade, pois isso configuraria, conforme aponta parte da doutrina alemã, violação à proibição de excesso (Übermaßverbot).

Um ponto negativo da legislação alemã e a referência à "esfera estritamente pessoal da vida". É que referida concepção se mostrou bastante polêmica e de difícil aplicação no caso concreto. Mais razoável é a vinculação da tutela penal não somente às imagens captadas e reproduzidas em habitações ou locais protegidos da vista, mas também às imagens que exibem cenas de nudez, bem como àquelas que exibem cenas comprometedoras, ofendendo a honra. Certamente a imagem merecerá maior proteção nessas situações, passando do campo meramente civil para a esfera penal.

Deve ser considerada exagerada a proteção penal autônoma da imagem, pois, se não houver a tipificação das condutas tão somente relacionadas à área de retiro da vítima, estar-seá arriscando a punição de ações com potencialidade lesiva irrelevante para o direito penal.

Por conseguinte, é mais acertada a tutela penal da imagem de forma não autônoma, mas em associação com a punição de determinados atentados a direitos da personalidade, como a violação da intimidade e da honra, o que é feito pelo Código Penal alemão. Assim sendo, o direito à imagem não deve ser erigido, em toda sua extensão e compreensão, como um bem jurídico tutelado de forma autônoma pelo direito penal.

\section{REFERÊNCIAS BIBLIOGRÁFICAS}

ANDRADE, Manuel da Costa. A tutela penal da imagem na Alemanha e em Portugal. Revista Brasileira de Ciências Criminais, v. 94, p. 133-175, 2012.

BORGMANN, Matthias. Von Datenschutzbeauftragten und Bademeistern - Der strafrechtliche Schutz am eigenen Bild durch den neuen § 201a StGB. Neue Juristische Wochenschrift, Frankfurt, ano 57, n. 30, p. 2133-2135, jul. 2004.

BOSCH, Nikolaus. Der strafrechtliche Schutz vor Foto-Handy-Voyeuren und Paparazzi. Juristenzeitung, v. 60, n. 8, p. 377-385, abr. 2005.

DIAS, Jorge de Figueiredo. Direito penal: parte geral. São Paulo: Revista dos Tribunais, 2007, t. I. 
DREYER, Gunda; KOTTHOFF, Jost; MECKEL, Astrid. Urheberrecht. 3. ed. Heidelberg: C. F. Müller, 2013.

EISELE, Jörg. Strafrecht - Besonderer Teil I. 4. ed. Stuttgart: Kohlhammer, 2017.

Strafrechtlicher Schutz vor unbefugten Bildaufnahmen. Juristische Rundschau, Berlin, p. 6-11, jan. 2005.

FISCHER, Thomas. Strafgesetzbuch und Nebengesetze. München: C.H. Beck, 2013.

GERTZEN, Anke Marie. Der strafrechtliche Schutz des Rechts am eigenen Bild: Eine Bewertung des § 201 a StGB im Vergleich zu Art. 197 Código Penal. Göttingen: Cuvillier, 2009.

GRAF, Jürgen-Peter. Vor $\S \S 201$ ff. $\S \S$ 201-202c. In: Münchener Kommentar zum Strafgesetzbuch. 2. ed. München: C. H. Beck, 2012, v. 4.

HELLE, Jürgen. Besondere Persönlichkeitsrechte im Privatrecht: das Recht am eigenen Bild, das Recht am gesprochenen Wort und der Schutz des geschriebenen Wortes. Tübingen: Mohr Siebeck, 1991.

HENGST, Florian. Der strafrechtliche Schutz des Rechts am eigenen Bild (\$ 201a StGB). Frankfurt am Main: Peter Lang, 2012.

HOYER, Andreas. Die Verletzung des höchstpersönlichen Lebensbereichs bei § 201a StGB. Zeitschrift für Internationale Strafrechtsdogmatik, ano 1, n. 1, p. 1-6, jan. 2006.

KÄCHELE, Andreas. Der strafrechtliche Schutz vor unbefugten Bildaufnahmen ( $\$ 201$ a StGB). Baden-Baden: Nomos, 2007.

KARGL, Walter. Zur Differenz zwischen Wort und Bild im Bereich des strafrechtlichen Persönlichkeitsschutzes. Zeitschrift für die Gesamte Strafrechtswissenschaft, v. 117, n. 2, p. 324-353, nov. 2005.

KINDHÄUSER, Urs. Strafrecht. Besonderer Teil I. Straftaten gegen Persönlichkeitsrechte, Staat und Gesellschaft. 8 ed. Baden-Baden: Nomos, 2017.

Strafrecht: Allgemeiner Teil. Baden-Baden: Nomos, 2015.

. Strafgesetzbuch. Lehr- und Praxiskommentar. 5. ed. Baden-Baden: Nomos, 2012.

KRAENZ, Nadja. Der strafrechtliche Schutz des Persönlichkeitsrechts. Baden-Baden: Nomos, 2008.

KÜHL, Kristian. Zur Strafbarkeit unbefugter Bildaufnahmen. Zeitschrift für Medien- und Kommunikationsrecht, Düsseldorf, ano 35, n. 3, p. 190-197, maio/jun. 2004.

LEFFLER, Ricarda. Der strafrechtliche Schutz des Rechts am eigenen Bild vor dem neuen Phänomen des Cyber-Bullying. Frankfurt am Main: Peter Lang, 2012. 
LEGLER, Thomas. La vie privée, image volée: la protection pénale de la personnalité contre les prises de vues. Berna: Staempfli, 1997.

MAURACH, Reinhart; SCHROEDER, Friedrich-Christian; MAIWALD, Manfred. Strafrecht Besonderer Teil. 10. ed. Heidelberg: C.F. Müller, 2009, v. 1.

RENGIER, Rudolf. Strafrecht Allgemeiner Teil. 7. ed. München: C. H. Beck, 2015. . Strafrecht. Besonderer Teil II. 14. ed. München: C. H. Beck, 2013.

ROXIN, Claus. A Proteção de bens jurídicos como função do direito penal. Porto Alegre: Livraria do Advogado, 2009.

. Strafrecht: Allgemeiner Teil. München: C.H. Beck, 2006, v. 1.

SCHMITZ, Albert. Strafrechtlicher Schutz vor Bild- und Wortaufnahmen. Hamburg: Dr. Kovac, 2011.

VALERIUS, Brian. § 201a. In: LAUFHÜTTE, Heinrich Wilhelm et alii. Strafgesetzbuch. Leipziger Kommentar. 12 ed. Berlin: De Gruyter, 2010, v. 6, p. 1391-1415.

WESSELS, Johannes; HETTINGER, Michael. Strafrecht Besonderer Teil. 41. ed. Heidelberg: C.F. Müller, 2017, v. 1.

ZANINI, Leonardo Estevam de Assis. Direito à imagem. Curitiba: Juruá, 2018.

. A tutela das criações intelectuais e a existência do direito de autor na Antiguidade Clássica. Revista Eletrônica da Faculdade de Direito de Franca, v. 8, n.1, p. 133-150, jul. 2013.

ZWEIGERT, Konrad; KÖTZ, Hein. Einführung in die Rechtsvergleichung: auf dem Gebiete des Privatrechts. 3. ed. Tübingen: Mohr Siebeck, 1996.

Data de Submissão: 24/08/2020

Data de Aceite: 07/08/2020 